\title{
ESTUDO DA CRISTALIZAÇÃO DA LACTOSE A PARTIR DA ADIÇÃO DE ETANOL
}

\author{
G. R. OLIVEIRA ${ }^{1}$, M. S. SANTOS ${ }^{1}$, A. L. BALIEIRO ${ }^{1}$, O. L. S. ALSINA ${ }^{1 *}$, A. S. LIMA ${ }^{1}$, C. M. \\ F. SOARES ${ }^{1}$ \\ ${ }^{1}$ Universidade Tiradentes, ITP/ENGENHARIA DE PROCESSOS \\ "e-mail: odelsia@uol.com.br
}

\begin{abstract}
RESUMO
Lactose é um dissacarídeo encontrado no leite e em vários produtos lácteos que possui um alto valor agregado devido às suas aplicações nas indústrias farmacêuticas e alimentícias. Apesar da sua importância, apenas uma pequena parcela da lactose produzida em laticínios é recuperada. Dentre as técnicas de recuperação possíveis, a cristalização tem apresentado algumas vantagens como a elevada pureza do produto final e a possibilidade de modificação de algumas propriedades do soluto, apenas com alteração da natureza do solvente. O objetivo deste trabalho foi estudar a recuperação da lactose por meio do processo de cristalização, utilizando um planejamento estatístico como ferramenta para análise da influência das variáveis, volume de etanol e tempo de agitação, bem como a otimização do processo. Os resultados obtidos mostraram que o volume de etanol apresentou uma significância estatística maior que o tempo de agitação, e aplicando análises térmicas verificou-se que as amostras de lactose recuperadas apresentaram propriedades semelhantes ao padrão de $\alpha$ alfa lactose utilizado.
\end{abstract}

\section{INTRODUÇÃO}

Lactose é a principal fonte de carboidrato encontrado no leite e em vários produtos lácteos. Ela é amplamente usada como excipiente na indústria farmacêutica, em especial na formulação de produtos para medicamentos e bastante utilizado na área alimentícia como suplemento em produtos alimentícios infantis, além de contribuir para a cor e o sabor de vários alimentos (SOUZA et al., 2010).

A indústria de laticínios produz grandes quantidades de lactose, contudo apenas uma pequena parcela do que é produzido é reaproveitada durante o processamento, enquanto que boa parte é desperdiçada, acarretando problemas em relação ao descarte e com a eliminação de resíduos.
Dentre as técnicas disponíveis para a separação de produtos orgânicos em soluções aquosas, a técnica de cristalização com a adição de um anti-solvente tem se mostrado promissora. Dentre as principais vantagens, destaca-se a possibilidade de reduzir a solubilidade do soluto, sem criar uma nova fase líquida proporcionando a formação de cristais de diferentes formas, quando um dos solventes é alterado (PATEL e MURTHY, 2011). BUND e PANDIT (2007) estudaram a recuperação rápida da lactose do soro do leite de búfala utilizando o etanol como antisolvente. Durante esse estudo, vários fatores como concentração de etanol, temperatura e $\mathrm{pH}$ foram avaliados. Resultados mostraram que foi possível uma recuperação de mais de 90\% para um tempo de agitação de uma hora e uma concentração de $85 \%$ v/v de etanol. TEIXEIRA et al. (2015) estudaram o processo 
de cristalização de lactose monohidratada em leito vibrado, com semeadura, utilizando um planejamento estatístico do tipo composto central. Os resultados obtidos apresentaram o nível de supersaturação, o adimensional de vibração e o tempo de cristalização como variáveis relevantes do processo.

O presente trabalho trata do estudo da recuperação da lactose por meio do processo de cristalização, utilizando um planejamento estatístico como ferramenta para análise da influência das variáveis, volume de etanol e tempo de agitação, bem como a otimização do processo.

\section{Materiais e Métodos}

Neste estudo foi utilizado no processo de cristalização o padrão de $\alpha$ lactose da e o etanol absoluto grau HPLC, ambos obtidos da Sigma Aldrich.

\subsection{Unidade Experimental}

O processo de recuperação da lactose por meio da cristalização foi realizado a partir da diluição de $6 \mathrm{~g}$ do padrão de $\alpha$ lactose em $20 \mathrm{~mL}$ de água MiliQ, mantida sob agitação constante de $735 \mathrm{rpm}$ no agitador magnético, como mostra a Figura 1. A solução foi inicialmente aquecida a $60{ }^{\circ} \mathrm{C}$ para garantir a completa dissolução e em seguida resfriada a temperatura de $25^{\circ} \mathrm{C}$ antes da adição do etanol. Após a adição, a solução foi filtrada utilizando Kitassato de borosilicato, funil de Buchner e papel filtro quantitativo porosidade $0,8 \mu \mathrm{m}$, ligados a uma bomba de vácuo como mostra a Figura 1, separada e secada num dessecador por um período de 24 horas antes do processo de pesagem.
Figura 1 - Unidade Experimental

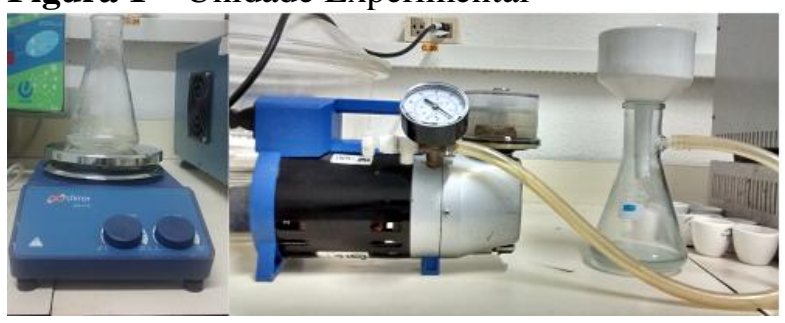

Fonte: Autor (2015).

\subsection{Planejamento Experimental}

Para avaliar a influência das variáveis no processo de recuperação da lactose, utilizou-se um planejamento experimental $2^{2}$, possuindo como fatores a concentração de etanol e o tempo de agitação, cujos níveis são apresentados na Tabela 1.

Tabela 1 - Níveis e fatores do planejamento experimental

\begin{tabular}{lccc}
\hline Fatores Nível & -1 & 0 & 1 \\
\hline \hline Volume de etanol (mL) & 40 & 50 & 60 \\
Tempo de agitação (min) & 10 & 35 & 60 \\
\hline
\end{tabular}

Os valores de volume e tempo de agitação foram escolhidos com base na literatura sobre estudos de recuperação da lactose por cristalização (KOUGOULOS; MARZIANO, e MILLER, 2010; PATEL e MURTHY, 2011). O processo de recuperação da lactose por cristalização foi realizado conforme planejamento apresentado na Tabela 2.

Tabela 2 - Planejamento Experimental

\begin{tabular}{lcc}
\hline Ensaio & $\begin{array}{c}\text { Volume de etanol } \\
(\mathrm{ml})\end{array}$ & $\begin{array}{c}\text { Tempo de } \\
\text { agitação (min) }\end{array}$ \\
\hline 1 & 40 & 10 \\
2 & 60 & 10 \\
3 & 40 & 60 \\
4 & 60 & 60 \\
$\mathrm{PC} 1 *$ & 35 & 35 \\
$\mathrm{PC} 2 *$ & 35 & 35 \\
Controle** & 50 & 60 \\
\hline
\end{tabular}

"Ponto Central (PC)

*** Controle (Sem Agitação) 


\section{Resultados e Discussão}

\subsection{Otimização das Condições de recuperação da lactose}

Os efeitos do volume de etanol e o tempo de agitação e suas interações sobre o processo de recuperação da lactose por cristalização foram avaliados empregando um delineamento $2^{2}$ com duplicata no ponto central. Ao planejamento, foi acrescentado um ponto de controle, sem agitação, para observar o efeito. Conforme as condições experimentais estudadas, a recuperação da lactose variou de $43,50 \%$ a $91,83 \%$ (Tabela 3).

Tabela 3 - Matriz Experimental e Resultados

\begin{tabular}{lccc}
\hline Ensaio & $\begin{array}{c}\text { Volume de } \\
\text { etanol (ml) }\end{array}$ & $\begin{array}{c}\text { Tempo de } \\
\text { agitação } \\
\text { (min) }\end{array}$ & $\begin{array}{c}\text { Recuperação } \\
(\%)\end{array}$ \\
\hline 1 & 40 & 10 & 52,70 \\
2 & 60 & 10 & 90,67 \\
3 & 40 & 60 & 86,67 \\
$\mathbf{4}$ & $\mathbf{6 0}$ & $\mathbf{6 0}$ & $\mathbf{9 1 , 8 3}$ \\
PC1 & 50 & 35 & 89,73 \\
PC2 & 50 & 35 & 89,13 \\
Controle & 50 & 60 & 43,50 \\
\hline
\end{tabular}

A partir dos dados de planejamento e dos resultados do processo, foi possível analisar as tendências por meio do software STATISTICA versão 7.0. No gráfico de Pareto como mostra a Figura 2 é possível avaliar a variável que exerceu maior influência no processo de recuperação da lactose.
Figura 2 - Gráfico de Pareto.

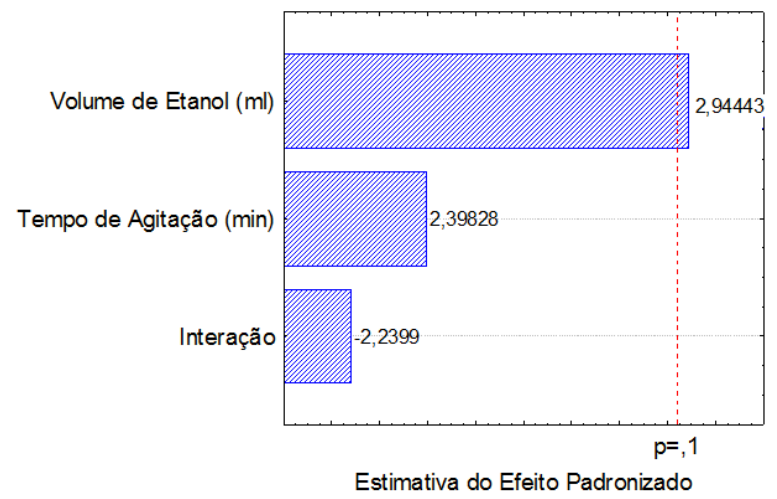

Fonte: Autor (2015)

De acordo com o gráfico de Pareto como mostra a Figura 2, apesar das variáveis estudadas influenciarem o processo de recuperação da lactose, o volume de etanol se mostrou mais significativo ao nível de confiança de 90\%. Após esta análise, foi obtido o modelo estatístico, baseado no método de regressão dos mínimos quadrados para a estimação dos parâmetros, conforme a Equação 1.

$$
R(\%)=-40,24+2,23 V+1,99 T-0,03 V T
$$

A Tabela 4 mostra os parâmetros da análise de variância (ANOVA).

Tabela 4 - Análise da variância para o ajuste do modelo linear de recuperação da lactose

\begin{tabular}{ccccc}
\hline Forma de & Somas dos & \multicolumn{3}{c}{ Graus de Quadrado $F_{\text {calculado }}$} \\
Variação & quadrados & Liberdade & médio & \\
\hline Regressão & 42837,89 & 4 & 10709,47 & 199,84 \\
Resíduos & 107,18 & 2 & 53,59 & \\
Total & 42945,07 & & & \\
\hline${ }^{*}{ }^{2}=95 \%$ & ${ }^{2} F_{\text {tabelado=9,24 }} 9$ & &
\end{tabular}

Observando os valores encontrados na Tabela 4, verifica-se que de acordo com o teste $\mathrm{F}$, o modelo é altamente preditivo, pois o $F_{\text {calculado }}$ foi bem maior que o $F_{\text {tabelado. Sendo o }}$ modelo estatisticamente significativo, podemse construir superfícies de resposta para verificar as condições que maximizem a recuperação da lactose. 
A superfície de resposta do planejamento fatorial experimental $2^{2}$ é apresentada na Figura 3, na qual se observa que a maior quantidade de lactose recuperada $(91,83 \%)$ se encontra na região onde o volume de etanol é $60 \mathrm{~mL}$ e o tempo de agitação é igual a $60 \mathrm{~min}$. Considerando o ponto de controle inserido no planejamento observou-se a importância da agitação, em virtude que a menor recuperação $(43,50 \%)$ ocorreu justamente quando a solução não foi agitada.

Figura 3 - Efeito do volume de Etanol e do tempo de agitação sobre a recuperação da lactose

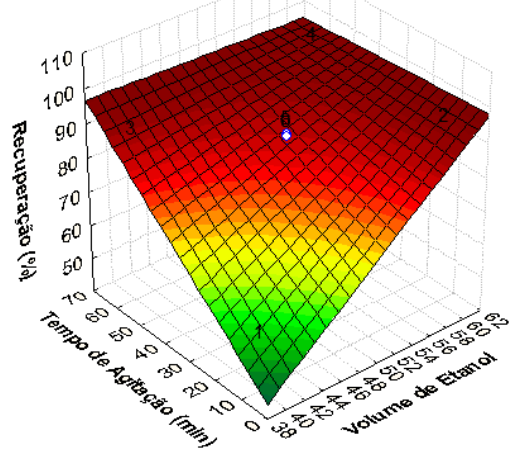

\subsection{Análises Térmica da lactose}

Com base nos resultados obtidos, as amostras que representaram a menor $(50 \mathrm{~mL}-$ 60min Sem Agitação) e maior (60mL-60min) recuperação, foram caracterizadas através da análise termogravimétrica e comparadas com as propriedades térmicas do padrão da $\alpha$ lactose utilizado na preparação das soluções estudadas. A partir das curvas térmicas obtidas conforme a Figura 4 foi possível determinar a região onde o material é termicamente estável até o momento em que toda fase orgânica é consumida. Essas curvas mostram que as amostras recuperadas apresentaram perfis similares a amostra padrão, indicando semelhanças na composição dos materiais. Nota-se que a de
$118{ }^{\circ} \mathrm{C}$ a $154{ }^{\circ} \mathrm{C}$ ocorre uma perda de massa da lactose que pode ser justificada pela a etapa de desidratação associada à perda de água da lactose. Entre $231{ }^{\circ} \mathrm{C}$ e $344{ }^{\circ} \mathrm{C}$ ocorre a maior perda de massa devido à fusão da lactose, que ocorre a uma temperatura de no mínimo $220{ }^{\circ} \mathrm{C}$. O processo de decomposição da amostra ocorreu em três etapas, de $344{ }^{\circ} \mathrm{C}$ a $400{ }^{\circ} \mathrm{C}$, entre $400{ }^{\circ} \mathrm{C}$ e $600{ }^{\circ} \mathrm{C}$ e de $600{ }^{\circ} \mathrm{C}$ a $1000{ }^{\circ} \mathrm{C}$ onde ocorreu praticamente a degradação completa da amostra.

Figura 4 - Curvas termogravimétricas da Lactose.

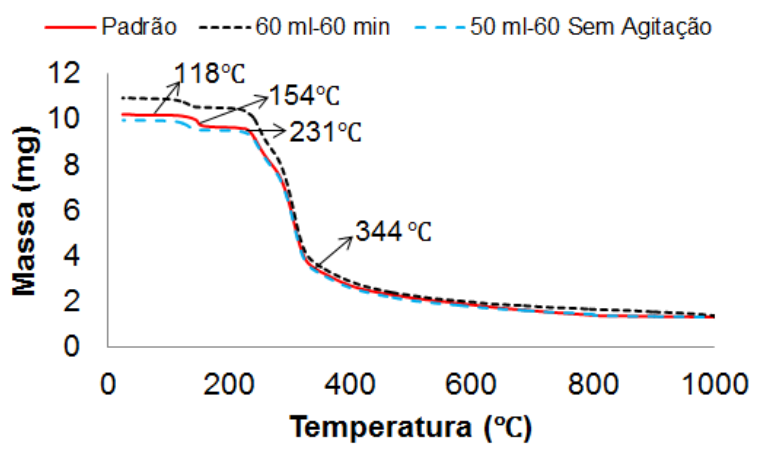

Fonte: Autor (2015).

\section{CONCLUSÃO}

O processo de recuperação da lactose usando o etanol com anti-solvente no processo de cristalização, se mostrou uma técnica eficiente apresentando um alto percentual de recuperação de 91,83\%. Utilizando o planejamento experimental foi possível observar que o volume de etanol apresentou uma significância estatística maior que o tempo de agitação. Porém, o ponto de controle inserido no planejamento mostrou que a eficiência do processo está diretamente relacionada com a agitação. As semelhanças entre as curvas térmicas das amostras recuperadas com o padrão de lactose evidenciaram a pureza do produto final, tornando a técnica de cristalização promissora. 


\section{REFERÊNCIAS}

BUND, R. K.; PANDIT, A. B. Rapid lactose recovery from buffalo whey by use of "antisolvent, ethanol". Journal of Food Engineering, v. 82, p. 333-341, 2007.

SOUZA, R. R. et al. Recovery and purification of lactose from whey. Chemical Engineering and Processing: Process Intensification, v. 49, n. 11, p. 1137-1143, 2010.

KOUGOULOS, E.; MARZIANO, I.;

MILLER, P. R. Lactose particle engineering: Influence of ultrasound and anti-solvent on crystal habit and particle size. Journal of Crystal Growth, v. 312, n. 23, p. 3509-3520, 2010.

PATEL, S. R.; MURTHY, Z. V. P. Waste valorization: Recovery of lactose from partially deproteinated whey by using acetone as anti-solvent. Dairy Science \& Technology, 2010.

SARTORI, D. J. M. Transferência de Calor em Leito Deslizante. 1986. 120p. Tese (Doutorado em Engenharia Química) Universidade Federal do Rio de Janeiro, Rio de Janeiro, 1986.

TEIXEIRA, G. A, FALCOMER, M. C. R., LOPES, L. F., FONTES, A. V., FINZER, J. R. D. Avaliação da cinética de crescimento de cristais de lactose em um cristalizador troncocônico de leito vibrado. Anais do XXXVI Congresso Brasileiro de Sistemas Particulados. Ed. Edufal, Maceió p. 14781484, 2015. 